\title{
A Healthcare Organization's Response to Challenges during a Pandemic
}

\author{
By: Debora O'Cathey, BSN, RN-BC; Judith Bowling, PhD, MHA, MSN, RN-BC
}

\begin{abstract}
The pandemic of 2020 has added many new challenges for healthcare organizations. Front-line nurses have borne the brunt of these challenges and were tested as never before to deliver excellent patient care during such arduous time. This story details the efforts of one hospital to rise above the chaos and overcome the challenges presented during this time.
\end{abstract}

Keywords: Challenges, pandemic, COVID-19, coronavirus

\section{AN ORGANIZATION'S REPONSE TO THE CHALLENGES OF PROVIDING HEALTHCARE DURING A PANDEMIC}

As one might anticipate, the coronavirus pandemic has added many new challenges for healthcare organizations. The working environment for healthcare organizations changes frequently during regular business times but operating an acute care hospital during a pandemic is a completely different situation. Recommendations for conducting business changed frequently to keep up with the latest information available on the SARS-CoV-2 virus (the virus causing COVID-19 disease). The Centers for Disease Control and Prevention (CDC) initially advised citizens not to wear masks, primarily due to concerns healthcare workers would not be able to get needed supplies (American Journal of Managed Care, 2020).

As the pandemic spread, however, the CDC recommended people wear masks when they were not able to maintain social distancing of six feet apart from others. Some professionals, such as Emergency Department physicians and public health officials, recommended wearing masks at all times, even when outside. The political scene was even more confusing, with some leaders allowing social gatherings fewer than 500 , then if less than 100, then if less than 50, then not allowed at all in some communities. The confusion was especially problematic for healthcare workers providing care to patients ill with COVID-19 (Bradley \& Chahar, 2020). Different recommendations from different sources resulted in confu- sion and chaos making the situation for healthcare leaders even more difficult. Hospital leaders worked diligently to keep the staff informed regarding the constantly changing "best" way to deliver care.

This story is about how one of those healthcare organizations rose to the challenges presented by the pandemic. One hospital, working with sister facilities in Southeast Florida, ensured all staff were prepared with the proper Personal Protection Equipment (PPE) to safely provide patient care. Staff received their own set of goggles and N99 masks with filters. The organization also provided resources for staff who were emotionally and mentally overwhelmed by the stress of the pandemic. Directors held pre-shift huddles via telephone to update the staff on the latest changes and what could be expected during the shift. Senior leaders from the corporate section of the organization sent out weekly updates via email, working persistently to keep staff informed. One group combed the literature to provide a concise and reliable guide to the latest information on the financial impact of the pandemic, transmission of the disease, status of PPEs, risk factors, diagnostic testing as well as the latest information from the news and social media. Even with these resources, direct care nurses bore the brunt of the onslaught of large numbers of sick due to SARS-CoV-2 virus.

The stress for direct care providers elevated to new heights when, due to safety concerns, patients were no longer permitted to have family or 
friends with them during their stay in the hospital. Patients relied on their nurse to keep their family informed about their condition. One example was a nurse working in the Emergency Department lobby as a screener when a group of people arrived looking for their loved one. The person for whom this group was searching had been brought to the hospital by Emergency Medical Services (EMS). Sadly, the nurse had to tell the family they could not see their family member due to restrictions to prevent spread of the coronavirus. The nurse did obtain contact information from the family members and provided them with the number to call for updates. After the family left the hospital, the patient's condition deteriorated, requiring intubation and she was subsequently transferred to another facility. Unfortunately, the patient did not have a positive outcome and the family were not able to see their loved one for a last visit.

These types of situations, when family cannot be at the bedside of their loved one, weigh heavily on the heart and soul of staff (Ehrlich, McKenney, $\&$ Elkbuli, 2020). Nurses understand that the family want to provide love and support for the patient. Nurses sympathize with every patient left to deal with such a trying situation alone, without support from their family.

The leaders of one hospital listened to the nurses and to the patients. One hospital provided resources for the staff to help them during these difficult situations, such as recruiting travel nurses to lighten the load. Staff were given discount rates at local hotels, so they did not need to endanger their family members by taking the coronavirus home from work. Reduced day care rates were offered so parents could continue to work without worrying about their child. The nurse in the example above stated she felt the organization demonstrated they cared about her, was concerned for her well-being and supported her during one of the most difficult times in her career.

Healthcare is a difficult profession in the best of times. The staff and the leaders have always realized no two days are alike and have learned to be flexible to meet the demands of the job. The pandemic definitely raised the bar for the staff and for the leaders. The nurses and leaders of this hospital rose to the challenges and will prevail throughout this pandemic because of the dedication to our patients and our staff.

\section{DECLARATION OF INTEREST}

The authors report no conflicts of interest. The authors alone are responsible for the content and writing of the paper.

\section{AUTHORS}

Debora O'Cathey, BSN, RN-BC Multispecialty Acute Care Center Nurse, Mariners Hospital, FL, US. Correspondence regarding this paper can be directed at: DeboraOC@baptisthealth.net

Judy Bowling, PhD, MHA, MSN, RN-BC, Nurse Scientist, Baptist Health South Florida, Miami, FL, US. Correspondence regarding this paper can be directed at: JudithB@baptisthealth.net

\section{REFERENCES}

American Journal of Managed Care (AJMC), (2020). A timeline of COVID-19

developments in 2020. https:// www.ajmc.com/view/a-timeline-of-covid19developments-in-2020

Bradley, M., \& Chahar, P. (2020). Burnout of healthcare providers during COVID-19 (published online ahead of print, $2020 \mathrm{Jul}$ 9). Cleveland Clinical Journal of Medicine. doi:10.3949/ccjm.87a.ccc051

Centers for Disease Control and Prevention (2020). Coronavirus Disease 2019. https:// www.cdc.govcoronavirus/2019-nCoV/ index.html

Ehrlich, H., McKenney, M., \& Elkbuli, A. (2020). Protecting our healthcare workers during the COVID-19 pandemic. The American Journal of Emergency Medicine, 38(7), 1527-1528. https:// doi.org/10.1016/j.ajem.2020.04.024

Turale, S., Meechamnan, C., \& Kunaviktkul, W. (2020). Challenging times: ethics, nursing, and the COVID-19 pandemic. International Nursing Review, 76(2), 164-167. https://doi.org/10.1111/inr.12598 